Modelling Complex Intermodal Freight Flows

Non Peer-reviewed author version

CARIS, An; JANSSENS, Gerrit K. \& Macharis, Cathy (2009) Modelling Complex Intermodal Freight Flows. In: Aziz-Alaoui, M. \& Bertelle, C. (Ed.) From System

Complexity to Emergent Properties, p. 291-300..

Handle: http://hdl.handle.net/1942/10820 


\title{
Modelling Complex Intermodal Freight Flows
}

\author{
An Caris ${ }^{1}$, Gerrit K. Janssens ${ }^{1}$ and Cathy Macharis ${ }^{2}$ \\ 1 Transportation Research Institute, Hasselt University - campus Diepenbeek, \\ Wetenschapspark 5 - bus 6, 3590 Diepenbeek, Belgium \\ $\{$ an. caris, gerrit. janssens $\}$ Quhasselt.be \\ 2 Department MOSI - Transport and Logistics, Vrije Universiteit Brussel - \\ Managementschool Solvay, Pleinlaan 2, 1050 Brussel, Belgium \\ Cathy.Macharis@vub.ac. be
}

Summary. In regions with an extensive waterway network intermodal transport including inland navigation is a good alternative for unimodal road transport. Intermodal transport networks exhibit an increased complexity due to the inclusion of multiple transport modes, multiple decision makers and multiple types of load units. A discrete event simulation methodology is proposed to understand the network dynamics and analyze policy measures with the intention of stimulating intermodal barge transport. The simulation model allows to quantify a number of network properties resulting from the interaction of freight flows. The intermodal hinterland network of the port of Antwerp serves as the real-world application in this study. Various aspects in the modelling process are discussed and a first potential policy is analysed.

\section{Introduction}

In this paper a discrete event simulation methodology is developed to capture and analyze the interactions in intermodal freight transport networks. Macharis and Bontekoning [6] define intermodal transport as the combination of at least two modes of transport in a single transport chain, without a change of container for the goods, with most of the route travelled by rail, inland waterway or ocean-going vessel and with the shortest possible initial and final journeys by road. Intermodal transport may include various transport modes. Our aim is to analyze the performance of intermodal networks including inland navigation and road transport. In regions with an extensive waterway network, such as Western Europe, intermodal transport including inland navigation is a good alternative for unimodal road transport.

Intermodal planning problems are more complex due to the inclusion of multiple transport modes, multiple decision makers and multiple types of load

units. In this paper an intermodal freight transport network is modelled with the objective to understand the system and analyze various network configurations. The complexity of the intermodal transport system makes it impossible 
to describe all interactions by a mathematical model. Because of this increased complexity and the required level of detail, discrete event simulation is the appropriate tool of analysis. A simulation model is created to support decisions in intermodal transport at the strategic level. The role of complex systems models in strategic decision making is discussed in [5]. The authors indicate that simulation models are appropriate to interpret the structure of a complex system. As stated in [1], the notions of emergence and emergent properties are not well defined. Emergent properties arise at a particular level of system description by virtue of the interaction of relatively simple lower-level components. The simulation model will allow to quantify a number of network properties resulting from the interaction of freight flows, as presented in section 2.5. Another example of modelling transportation networks as complex systems can be found in [10]. The objective of the authors is to study the emergence of hierarchies in the network.

Simulation models have been widely used to optimize the design of intermodal terminals. For example, Rizzoli et al. [9] present a simulation tool for the combined rail/road transport in intermodal terminals. Parola and Sciomachen [8] describe a strategic discrete event simulation model to analyze the impact of a possible future growth in sea traffic on land infrastructure in the north-western Italian port system. We develop a simulation model that covers the hinterland waterway network of a major port in Western-Europe in order to analyze effects of future policy measures for intermodal container transport. A first policy related to the consolidation network is presented in this paper. Various studies discuss consolidation strategies for intermodal transport by rail, see for example [2] and [7]. [3] presents and evaluates a consolidation strategy for intermodal transport by barge, based on a marginal cost model. In our simulation model the operations of the inland navigation network are modelled in detail. This enables us to examine ex-ante what the effects of a certain consolidation strategy will be and to take into account interaction effects in container flows. In the future, the model will also be used to analyze other policies related to intermodal barge transport. The simulation model is part of a larger decision support system for intermodal transport policy making which will not be discussed here.

\section{Modelling Methodology}

In this section the methodology to model the hinterland waterway network is described. First, the main characteristics of the intermodal network under investigation are given. Next, the conceptualization of the network is developed. The inputs and outputs of the simulation model are discussed. In the final subsection special attention is given to the functioning of the locks. 


\subsection{Intermodal Transport Network}

The intermodal hinterland network of the port of Antwerp serves as the realworld application in our study. In Belgium three regions of origin can be identified in the network. The first group of container terminals is situated along the Albert Canal towards the eastern part of Belgium. A second region of origin is located in the central part of the country, connected to the port of Antwerp by the Brussels - Scheldt Sea Canal. The third group of intermodal container flows originates in the basin of the Upper Scheldt and the river Leie. All intermodal container terminals organize shuttle services either to the port of Antwerp or to the ports of Rotterdam and Amsterdam. Two clusters of sea terminals can be identified in the port area of Antwerp. Until recently the main center of activity was situated on the right river bank. With the construction of a new dock (Deurganckdok) in the port of Antwerp, a second cluster of sea terminals emerged on the left river bank. Barges sail through the Scheldt-Rhine connection to Rotterdam and Amsterdam. A last destination is the port of Zeebrugge, which can be reached via Antwerp and navigation on the river Scheldt. Table 1 summarizes all origins and destinations of shuttle services. Shuttle services transport containers from inland terminals to sea terminals in the port area and carry containers from sea terminals to inland destinations in a round trip.

Table 1. Origins and Destinations

\begin{tabular}{ll}
\hline Origins & Destinations \\
\hline Albert Canal & Antwerp: right river bank \\
Brussels-Scheldt Sea Canal Antwerp: left river bank \\
Upper Scheldt and Leie & Rotterdam \\
& Amsterdam \\
& Zeebrugge \\
\hline
\end{tabular}

\subsection{Conceptual Model}

Three major components can be identified in the intermodal hinterland network, as depicted in Fig. 1. The first component in the intermodal freight transport network is the inland waterway network. The inland waterway network is made up of terminals, waterway connections and container flows. Entities are defined as barges which originate from the different inland terminals and carry containers in round trips to the various ports. A second component is the port area of Antwerp. Barges may visit sea terminals at the left river bank and right river bank in the same round trip, go to Rotterdam or Amsterdam via the Scheldt-Rhine connection or sail to Zeebrugge via the Scheldt estuary. On the right and left river bank, barges queue for handling at the sea 
terminals. Barges moor as soon as enough quay length is available. The handling time at the sea terminal depends on the number of containers that need to be unloaded from or loaded into the inland vessel. In the inland waterway network as well as in the port area multiple locks are present. Therefore, the lock planning constitutes a third major component, which will be discussed hereafter.

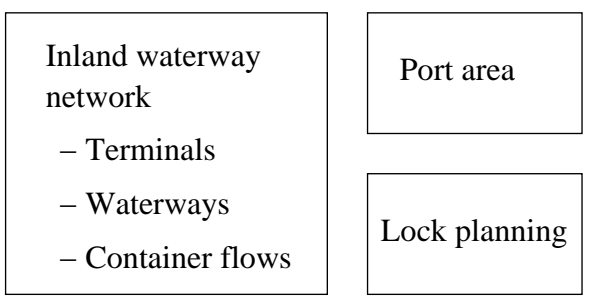

Fig. 1. Components

The objective of the model is to simulate possible policy measures for intermodal barge transport. Consequences and implications can be estimated before implementation of the policy measure. Therefore, various conceptual models may be necessary to analyze the implications of proposed policies. The conceptual model of the current container flow is depicted in Fig. 2. At present all barges enter the port area and visit one or multiple sea terminals.

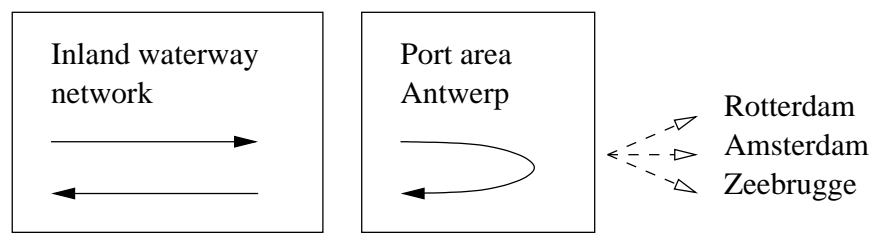

Fig. 2. Conceptual Model Current Situation

\subsection{Assumptions}

A number of assumptions are made to translate the actual intermodal network into a discrete event simulation model. The emphasis lays on inland waterway transport. Rail connections in the hinterland network are not taken into account. The model further assumes a homogeneous container type and equal handling time for each container. All main waterway connections between inland terminals and the port area are incorporated in the simulation model. Small waterways without inland terminals are not included in the simulation model of the current situation. Sailing times are assumed to be stochastic 
and follow a probability distribution. The average sailing time varies with the type of barge. A probability distribution is also used to model the stochastic lockage time.

\subsection{Data Requirements}

All intermodal terminals in the inland waterway network were asked for information to identify the container flows. Real data on shuttle services is used as an input for the simulation model, constructed in the simulation software Arena. For each shuttle service the following information is required: which type of barge is used, which destinations are visited and what is the average number of import and export containers for each destination. Container transport interacts with other freight flows. Therefore, the flow of non-containerized goods on the inland waterway network is introduced as an input in the simulation model. These flows affect the waiting times at locks. Information is also necessary on the network connections. The waterway administrators provided information on the number of locks on each waterway, distances between locks, average lockage times, number of lock chambers and size of the chambers. In the port area of Antwerp three clusters of locks connect the inner port area with the sea side. Data is required on the choice of locks when sailing in the port area. The average quay length available for handling inland navigation at sea terminals gives an indication of the service capacity in the port area of Antwerp. The port authority is asked for the average mooring time and time for loading and unloading in order to model the service times of inland container barges in the port area. Finally, an enquiry is made into the turnaround times of vessels and average waiting times at locks in order to verify and validate the model.

\subsection{Outputs}

Table 2 gives an overview of properties measured in the simulation model. The turnaround time of shuttles is defined as the total time necessary for a barge to sail from an inland container terminal to the port area, visit all sea terminals and return to the inland terminal. The turnaround time depends on the waiting times at locks and in the port area. The outputs measured at locks are the percentage of barges that have to wait, the number of barges that have to queue and the waiting time of barges in the queue. In the port area the waiting time before handling is measured, as well as the number of vessels queueing for service. A final group of performance measures concerns the capacity utilization. In the port area this is expressed as the average percentage of quay length occupied. In the hinterland network the average and maximum number of barges on each network connection is recorded. 
Table 2. Outputs

\begin{tabular}{ll}
\hline Shuttles & turnaround time \\
\hline Locks & $\begin{array}{l}\text { total number waiting (\%) } \\
\text { number waiting in queue } \\
\text { waiting time in queue }\end{array}$ \\
\hline Port area & $\begin{array}{l}\text { waiting time in queue } \\
\text { number waiting in queue }\end{array}$ \\
\hline Capacity utilization & quay length \\
& network connections
\end{tabular}

\subsection{Locks}

The operations of locks strongly affect waiting times of barges for lockage. A number of decision rules are defined to make the operations of the locks in the simulation model reasonably realistic. A first decision rule relates to the size of a barge. Barges are assigned to a lock chamber only if its size is within the allowed dimensions. Secondly, barges are assigned to the smallest lock chamber that is open. This decision rule focuses on a rapid lockage process of barges. Smaller lock chambers have a shorter lockage time. On the other hand, a more intensive use of larger lock chambers may reduce waiting times because more barges can be serviced simultaneously. A third decision rule is applied when no lock chamber is open in the sailing direction of the barge. In this situation the barge is assigned to the lock chamber which is the first available. A final decision rule concerns the closing of lock chambers. A lock chamber is closed when there is not enough remaining space for the next barge in queue or when no additional barges arrive within a predefined number of time units. From interviews with waterway administrators it appears that the operations of locks are entrusted to a lockkeeper, without fixed rules. Future research could introduce more complex decision rules in the simulation model.

\section{Analysis of Container Flows}

The simulation model will be used to analyze policy measures that impact container flows in the intermodal hinterland network and the port area of Antwerp. In this section a first policy measure is analyzed. A potential policy might be the introduction of an intermodal barge hub in the port of Antwerp, from which load is distributed to the different sea terminals, as described by Konings [3]. The author proposes to split existing barge services into a trunkline operation in the hinterland and collection/distribution operations in the seaport. This leads to the conceptual model depicted in Fig. 3.

By doing so inland barges do not have to call at multiple sea terminals. They only visit the intermodal barge hub. The intermodal hub organizes shut- 


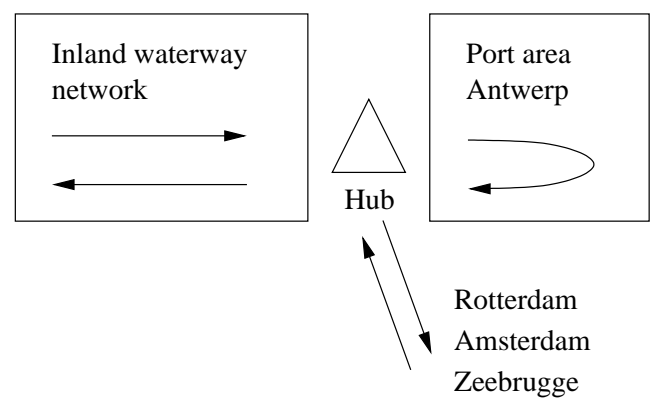

Fig. 3. Conceptual Model Future Situation

tle services in the port area to collect containers from and distribute containers to all sea terminals. In the collection/distribution network containers with the same origin or destination can be bundled. This enables a more efficient and prompt handling of barges at sea terminals. When modeling the new situation, it is assumed that all containers are collected and distributed by barge in the port area. In reality some containers might be transferred by road when the distance between the hub and the sea terminal is small or in urgent cases. The intermodal barge hub is located in the cluster of sea terminals on the right river bank. A quay length of 500 metres is assumed at the hub. To set a service level for the hub, it is required that all inland containers are delivered within 24 hours to the sea terminals. It is further assumed that two shuttle services are organized per day in the collection/distribution network, one in the morning and one in the afternoon, each visiting terminals on the right and/or left river bank. The shuttle services are carried out with vessels of a size of 96 TEU and 196 TEU. The organization of the collection/distribution network might be optimized. However, this setting already gives an indication of possible improvements in the relevant performance measures. When comparing the current situation with the new consolidation strategy, no changes are made to the schedules of the inland terminals. It is possible that inland terminals change their departures in the new situation. Other measures to enhance the efficiency can be further simulated. A separate random-number stream is dedicated to each source of randomness in the model in order to synchronize both alternatives as much as possible.

Performance measures relevant for the comparison of the scenarios are discussed next. Ten simulation runs of 672 hours are performed. Table 3 gives the average turnaround times of all inland terminals, expressed in hours. Inland vessels may only sail to Antwerp (Antw) or they can make a combined trip to Antwerp and Rotterdam (Rdam) or Amsterdam (Adam). Standard deviations are mentioned between brackets below the average turnaround times.

Table 4 summarizes performance measures in the port area. The average and maximum waiting time before handling, expressed in hours, are given for the sea terminals on the right and left river bank and at the intermodal barge 
Table 3. Average turnaround times current situation and intermodal barge hub

\begin{tabular}{lll}
\hline Avg turnaround time & Current Hub \\
\hline Deurne - Antw & 15.20 & 9.93 \\
& $(0.47)$ & $(0.35)$ \\
Deurne - Antw/Rdam & 22.08 & 22.98 \\
& $(0.89)$ & $(0.29)$ \\
Meerhout - Antw & 29.24 & 25.59 \\
& $(0.47)$ & $(0.18)$ \\
Meerhout - & 41.70 & 39.68 \\
Antw/Rdam/Adam & $(0.38)$ & $(0.89)$ \\
Genk - Antw & 38.97 & 35.94 \\
& $(0.62)$ & $(0.72)$ \\
Genk - Antw/Rdam & 49.89 & 47.24 \\
& $(0.87)$ & $(0.48)$ \\
Luik - Antw & 46.46 & 42.10 \\
Gent - Antw & $(0.34)$ & $(0.12)$ \\
& 20.62 & 19.43 \\
Wielsbeke - Antw & $(0.49)$ & $(0.42)$ \\
Avelgem - Antw & 38.62 & 39.60 \\
& $(0.42)$ & $(0.41)$ \\
Avelgem - Antw/Rdam & 41.19 & 40.78 \\
& $(0.88)$ & $(2.10)$ \\
Willebroek - Antw & $(0.48)$ & 61.89 \\
Willebroek - Antw/Rdam & 14.79 & 14.37 \\
Grimbergen - Antw & $(0.59$ & 34.917 \\
Brussel - Antw & 20.93 & $(0.14)$ \\
Brussel - Antw/Rdam & 21.91 & 22.42 \\
Herent - Antw & $(0.34)$ & $(0.17)$ \\
& $(0.29)$ & $(0.42)$ \\
& 21.91 & 21.68 \\
& $(0.19)$ & $(0.40)$ \\
\hline
\end{tabular}

hub. Next, the average and maximum utilization of the quays on the right and left river bank and at the hub are measured.

Following [4], paired- $t$ confidence intervals are constructed to compare the results. Table 5 presents the $95 \%$ confidence intervals for which the difference between the current situation and the intermodal barge hub is significant.

The average turnaround times of shuttles between inland terminals along the Albert Canal and the port of Antwerp are all significantly reduced. The maximum turnaround times of these inland terminals also decrease signifi- 
Table 4. Performance measures in the port area: current situation and intermodal barge hub

\begin{tabular}{lll}
\hline Port area & Current Hub \\
\hline Avg waiting time & & \\
Right river bank & 0.0629 & 0.0000 \\
& $(0.0306)$ & $(0.0000)$ \\
Left river bank & 0.0557 & 0.0000 \\
& $(0.0115)$ & $(0.0000)$ \\
Hub & $/$ & 0.2970 \\
& & $(0.0334)$ \\
\hline Max waiting time & & \\
Right river bank & 7.6128 & 0.0000 \\
Left river bank & 4.3095 & 0.0000 \\
Hub & $/$ & 8.4450 \\
\hline Avg capacity utilization & & \\
Quay Right river bank & 0.1666 & 0.1398 \\
& $(0.0017)$ & $(0.0014)$ \\
Quay Left river bank & 0.1741 & 0.1808 \\
Quay Hub & $(0.0017)$ & $(0.0016)$ \\
& $/$ & 0.2682 \\
& & $(0.0022)$ \\
\hline Max capacity utilization & & \\
Quay Right river bank & 0.9834 & 0.7867 \\
Quay Left river bank & 0.9850 & 0.6983 \\
Quay Hub & $/$ & 1.0000 \\
\hline
\end{tabular}

cantly due to the introduction of the hub. Shuttles originating from the Albert Canal can go directly to the intermodal barge hub without needing to pass through a lock in the port area. Shuttles from other inland terminals first have to pass through one of the locks to reach the hub. A reduction in turnaround time is also recorded for the terminal in Grimbergen. Table 4 shows that with an equal available quay length, shuttle services in the collection/distribution network of the new consolidation strategy do not have to wait for handling at sea terminals on the right and left river bank. The sea terminals can handle inland containers more efficiently because only shuttle services with consolidated load moor for service. The waiting time at the intermodal hub depends on the available quay length. A quay length of 500 metres is assumed and leads to an average waiting time of 17.82 minutes. Time windows could be negotiated with the inland terminals to reduce the waiting time at the hub at peak hours. Average capacity utilization on the right river bank decreases significantly. Finally, table 4 reveals that at peak moments the maximum capacity utilization decreases with $28.67 \%$ on the left river bank and with $19.67 \%$ on the right river bank. Less quay length is necessary to handle inland contain- 
Table 5. Confidence intervals for comparing the current and new situation

\begin{tabular}{ll}
\hline & $\begin{array}{l}\text { Confidence interval } \\
\text { hub - current }\end{array}$ \\
\hline Avg turnaround time & \\
Deurne - Antw & $-6.9143 ;-3.6159$ \\
Meerhout - Antw & $-4.7188 ;-2.5713$ \\
Genk - Antw & $-4.8083 ;-1.2481$ \\
Genk - Antw/Rdam & $-5.1158 ;-0.1897$ \\
Luik - Antw & $-5.2091 ;-3.5234$ \\
Grimbergen - Antw & $-2.4003 ;-0.6144$ \\
\hline Avg waiting time & \\
Left river bank & $-0.0818 ;-0.0297$ \\
\hline Avg capacity utilization & \\
Quay Right river bank & $-0.0304 ;-0.0233$ \\
\hline
\end{tabular}

ers at peak hours. These figures demonstrate the efficiency improvements at the sea terminals in the port area. No significant influence was found of the new consolidation strategy on waiting times at locks in the port area. Inland barges constitute only a small part of total lock passages.

\section{Conclusions and Future Research}

Intermodal freight transport networks can be seen as complex systems, showing properties that cannot be deducted from the individual components of the network. A discrete event simulation model is constructed to understand the network system and analyze network configurations. Various aspects in the modelling process are presented and network properties are discussed. Potential improvements to the model include the introduction of more complex decision rules for the operations of locks. A submodel could also be introduced to integrate the intermodal terminal planning into the simulation model.

The model will be used to make a quantitative ex-ante analysis of policy measures to stimulate intermodal barge transport. Simulation results of a first policy are presented. The introduction of an intermodal barge hub on the right river bank leads to a significant reduction in average and maximum turnaround times of shuttle services originating from the Albert Canal. This implies shorter and more stable sailing schedules for inland terminal operators along this waterway axis. However, no significant influence is found on the shuttle services of other inland terminals. Average capacity utilization on the right river bank decreases significantly. Inland containers are handled more efficiently at the sea terminals due to the consolidation of load in the collection/distribution network. Future simulation experiments will investigate the effect of a hub on the left river bank or the introduction of a multihub service 
model. Various scenarios may be compared to determine the most beneficial consolidation strategy.

Acknowledgement: We thank the Belgian Science Policy (BELSPO) for their support on our research project DSSITP (Decision Support Systems for Intermodal Transport Policy) in the research programme "Science for a Sustainable Development - call 2", under contract number SD/TM/08A.

\section{References}

[1] R.I. Damper. Emergence and levels of abstraction. International Journal of Systems Science, 31, 2000.

[2] Milan Janic, Aura Reggiani, and Peter Nijkamp. Sustainability of the European freight transport system: evaluation of innovative bundling networks. Transportation Planning and Technology, 23:129-156, 1999.

[3] Rob Konings. Smart collection and distribution of containers on barge in the port of Rotterdam. Proceedings of the Nectar Conference 2005, Las Palmas, Gran Canaria, 2005.

[4] Averill M. Law. Simulation modeling \& analysis. McGraw Hill, fourth edition, 2007.

[5] M.H. Lyons, I. Adjali, D. Collings, and O. Jensen. Complex systems models for strategic decision making. BT Technology Journal, 21(2):1127, 2003.

[6] Cathy Macharis and Yvonne M. Bontekoning. Opportunities for OR in intermodal freight transport research: A review. 153:400-416, 2004.

[7] Alexandra M. Newman and Candace Arai Yano. Scheduling direct and indirect trains and containers in an intermodal setting. Transportation Science, 34(3):256-270, 2000.

[8] Francesco Parola and Anna Sciomachen. Intermodal container flows in a port system network: Analysis of possible growths via simulation models. International Journal of Production Economics, 97:75-88, 2005.

[9] Andrea E. Rizzoli, Nicoletta Fornara, and Luca Maria Gambardella. A simulation tool for combined rail/road transport in intermodal terminals. Mathematics and Computers in Simulation, 59:57-71, 2002.

[10] Bhanu M. Yerra and David M. Levinson. The emergence of hierarchy in transportation networks. The Annals of Regional Science, 39:541-553, 2005. 